\title{
REVIEW
}

\section{Edible Oils Adulteration: A Review on Regulatory Compliance and Its Detection Technologies}

\author{
Choon Hui Tan ${ }^{1,2}$, lanne Kong ${ }^{1}$, Umair Irfan², Mahmud Iwan Solihin ${ }^{3}$, and \\ Liew Phing Pui ${ }^{1,2 *}$ \\ ${ }^{1}$ Functional Food Research Group, Faculty of Applied Sciences, UCSI University, No.1 Jalan Menara Gading, Cheras 56000 Kuala Lumpur, \\ MALAYSIA \\ ${ }^{2}$ Department of Food Science and Nutrition, Faculty of Applied Sciences, UCSI University, No.1 Jalan Menara Gading, Cheras 56000 Kuala \\ LUTMUI, MALAYSIA \\ ${ }^{3}$ Mechanical and Mechatronics Department, Faculty of Engineering, Technology and Built Environment, UCSI University, No.1 Jalan Menara \\ Gading, Cheras 56000 Kuala Lumpur, MALAYSIA
}

\begin{abstract}
Various events of edible oils adulteration with inferior ingredients were reported regularly in recent years. This review is aimed to provide an overview of edible oils adulteration practices, regulatory compliance and detection technologies. Many detection technologies for edible oils adulteration were developed in the past such as methods that are based on chromatography or spectroscopy. Electrochemical sensors like electric nose and tongue are also gaining popularity in the detection of adulterated virgin olive oil and virgin coconut oil. It can be concluded that these detection technologies are essential in the combat with food adulterers and can be improved.
\end{abstract}

Key words: edible oil adulteration, regulatory compliance, chromatography, spectroscopy, electronic tongue and nose

\section{Introduction}

Edible oils are defined as a food commodity of any kind of origin, source or structure that is manufactured for human intake entirely or in portion from a fat or oil other than dairy products ${ }^{1}$. To prepare delicious food, edible oils are often used due to its texture and exceptional flavour attributes. For many years, people utilized oil to make the flavour of the food better ${ }^{2}$. It is one of the indispensable nutrition components in our daily diet ${ }^{3)}$. The overall production of edible oil in India was 25.3 million tonnes in 2015-16 and the total area under edible oils was 26.13 million hectares. Total production of edible oils was recorded in 2013-14, which amounted to 32.75 million tonnes from 28.05 million hectares. India imported 148.2 metric tonnes of edible oils in 2015-16 and net domestic availability was 86.37 metric tonnes ${ }^{4)}$.

Adulteration in food commodities is a frequently faced problem in the current food business. Nearly all food commodities are subjected to quality problems, especially those having high commercial values ${ }^{5)}$. The substitution of expensive materials with cheaper ingredients can be very profitable for a producer or trader of raw ingredients since vending the product as if it remained pure permits profit values to be highly amplified ${ }^{6)}$. Owing to the growing demand of edible oils on the domestic and foreign markets, high-priced oil adulterated with low-priced oil is a major issue that can further threaten consumer health. For instance, extra virgin olive oil(EVOO), which is the highest quality of olive oil, is the most prone to fraudulent activi$t^{7}{ }^{7}$. In addition to possibly preventing olive oils from meeting extra virgin requirements, adulteration will reduce the presence of EVOO in a product and can in turn reduce its associated health benefits and flavour qualities ${ }^{7}$.

Unscrupulous businessmen also adulterate high-quality oil with used frying oil, which is a potential health risk for consumers $^{8}$. Consumers are facing all kind of health issues while consuming adulterated foods because they cannot differentiate between real and adulterated foods with their naked eyes ${ }^{8)}$. Therefore, food-related organisations need to establish and use effective methods to detect such adulterations, which will then ensure the authenticity and purity of edible oils and fats. Advanced and suitable techniques

\footnotetext{
*Correspondence to: Liew Phing Pui, Department of Food Science and Nutrition, Faculty of Applied Science, UCSI University, No.1 Jalan Puncak Menara Gading, Cheras 56000 Kuala Lumpur, MALAYSIA

E-mail: puilp@ucsiuniversity.edu.my ORCID ID: https://orcid.org/0000-0001-5305-4334

Accepted June 2, 2021 (received for review March 27, 2021)

Journal of Oleo Science ISSN 1345-8957 print / ISSN 1347-3352 online

http://www.jstage.jst.go.jp/browse/jos/ http://mc.manusriptcentral.com/jjocs

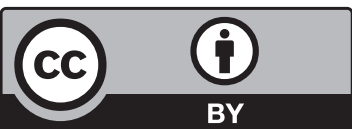


are being developed and currently being used to identify adulteration in edible oils that can help reduce consumer health risks. This paper provides a comprehensive review on the adulteration of edible oils and their detection methods. The regulatory compliance of edible oils in different countries will also be outlined.

\section{Regulatory Compliance of Edible Oils}

Food regulations include the legislative authority and the necessary legal structure for food control activities. The main objective is to protect the health of consumers from fraud by ensuring the important quality and health of food. According to Malaysian Food Regulation 1985, it stated that edible oils and fats must not contain adulterants, rancidity, offensive odour and taste. Edible oil in its single form shall be free from admixtures with other fats or oils. However, permitted food conditioners and antioxidants are allowed to be applied to the edible oils and fats as stated in the regulations. Blending of edible oils is acceptable as long as it meets the standard specifications established for edible oil in the regulations and cannot contain more than $30 \mathrm{~g} / \mathrm{kg}$ of unsaponifiable content. There are different standards for different kinds of edible oils stated in Malaysia Food Regulation 1985, as shown in Table 1.

In Thailand, edible fats and oils must be free from foreign matter and rancid odour in compliance with the requirements stated out in the regulations ${ }^{9)}$. The blending of edible fats and oils consisting of two or more different types of fats and oils is permitted as long as the processes are approved by the Thailand Food and Drug Administration(Thai FDA) either by mechanical process, inter-esteri- fication process or by other processes. Moreover, the action of blending edible oils shall comply with the additional standard or specification approved by the Thai FDA, as the condition may be $\mathrm{b}^{9)}$. As far as India is concerned, the blending of edible oils is permitted as long as the proportion by weight of any edible vegetable oil used in the blend is not less than $20 \%{ }^{10}$ ). It is allowed as long as the edible oils comply with the respective requirements established in the regulations. The blend must be clear and also be free from rancidity, suspended or insoluble matter or any other foreign matter, separated water, added colouring matter, flavouring substances, mineral oil, or any other animal and non-edible oils, or fats, argemone oils, hydrocyanic acid, castor oil and tricresyl phosphate ${ }^{10)}$.

In Brunei, the modification of fats and oils in edible oils and fats is permitted, and these foods are usually recognised as healthy ${ }^{11)}$. Unless otherwise stated, edible fats and oils must have a peroxide value of no more than 10 milliequivalents of peroxide oxygen per kilogram of fat or oil ${ }^{11}$. They may also contain permitted antioxidants. There are no regulations stating whether or not the blending of edible oils is permitted or prohibited. There are, however, requirements for vanaspati, a desi vegetable ghee made from a mixture of groundnut oil, cotton seed oil, sesame oil, or a combination of these oils, as well as other vegetable oils that are safe to eat ${ }^{11)}$. As a result, blending of harmless vegetable oil is permitted to make vanaspati as long as it complies with the respective requirements established in Brunei's Public Health (Food) Regulations.

According to Codex Alimentarius Commission ${ }^{12)}$, food additives such as colouring in edible oils and fats are permitted to restore the natural colour lost during processing or for colour standardisation purposes without misleading the user. Flavoring is also permissible as long as the ingre-

Table 1 Standards for different edible oils stated in Malaysia Food Regulation 1985.

\begin{tabular}{lccccc}
\hline \multicolumn{1}{c}{ Edible oil } & Specific gravity & Refractive index & $\begin{array}{c}\text { Saponification } \\
\text { value }(\mathrm{mg})\end{array}$ & Iodine value & $\begin{array}{c}\text { Unsaponifiable } \\
\text { matter }(\mathrm{g} / \mathrm{kg})\end{array}$ \\
\hline Coconut oil & $0.915-0.920$ & $1.448-1.449$ & $248-264$ & $7.5-10.5$ & $<5$ \\
Corn oil & $0.917-0.925$ & $1.465-1.480$ & $187-195$ & $103-130$ & $<28$ \\
Cottonseed oil & $0.915-0.928$ & $1.458-1.474$ & $189-198$ & $99-119$ & $<15$ \\
Peanut oil & $0.914-0.917$ & $1.460-1.465$ & $187-196$ & $80-106$ & $<10$ \\
RBD palm oil & $0.8900-0.8932$ & $1.450-1.460$ & $190-209$ & $50-55$ & $<10$ \\
Olive oil & $0.910-0.916$ & $1.4677-1.4705$ & $184-196$ & $75-94$ & $<15$ \\
Rice bran oil & $0.910-0.920$ & $1.4600-1.4700$ & $175-195$ & $90-105$ & $<30$ \\
Rapeseed oil & $0.910-0.920$ & $1.465-1.469$ & $168-181$ & $94-120$ & $<20$ \\
Safflower seed oil & $0.922-0.927$ & $1.467-1.470$ & $186-198$ & $135-150$ & $<15$ \\
Sesame seed oil & $0.915-0.923$ & $1.465-1.469$ & $187-195$ & $104-120$ & $<20$ \\
Sunflower seed oil & $0.918-0.923$ & $1.467-1.469$ & $188-194$ & $110-143$ & $<15$ \\
Soya bean oil & $0.919-0.925$ & $1.466-1.470$ & $189-195$ & $120-143$ & $<15$ \\
\hline
\end{tabular}


dients used comply with the requirements specified in the Codex Alimentarius Committee ${ }^{12)}$. However, it is mentioned in Codex Alimentarius Commission that no additives can be applied to virgin or cold pressed oils so as not to alter the oil ${ }^{12)}$. Virgin and cold pressed oils can only be obtained by mechanical procedures only, expelling or pressing, without the application of heat. After that, they may also have been purified by washing with water, settling, filtering and centrifuging only. There is no mention, however, of whether or not the mixing of edible oils and fats is permitted. Table 2 shows the standards for different edible oils stated in Codex Alimentarius Commission ${ }^{12)}$.

\section{Types of Edible Oils Adulteration}

Adulteration of edible oil is not a new issue and can happen in any given area or country. One of the reasons for edible oil adulteration is to capitalise on consumer demands and raise profits. Products with lower economic value are often mixed with higher priced commodities to improve on profits. For example, from an economic point of view, replacing high priced oil with cheaper oil is so profitable for producers and encourages them to do $\mathrm{so}^{13)}$. One of the most reported cases was the mixing of cottonseed oil imported into Egypt with palm oil produced in Malaysia ${ }^{14)}$. Another case based on Rossell, was the reconstitution of palm oil by mixing linpalm stearin and palm oil in a Singapore cocktail ${ }^{14)}$. By replacement of more expensive oils and fats with cheaper one, often result in a blend deviating from the mixture proportions displayed on the label, or if the blend is traded as authentic, the vendor will ultimately commit fraud ${ }^{15)}$. This will also have an effect on honest suppliers who suffer unfair competition ${ }^{15)}$.

On the other hand, minimally processed foods have gained broad interest in most of the countries. Since many people claim that these foods have superior nutritional qualities, mainly because their "naturalness" can be achieved to a higher degree by intentionally avoiding conventional food processing techniques such as refining ${ }^{15}$. Cold press oil obtained by mechanical means is usually manufactured using only the highest quality raw materials, otherwise it can cause deterioration during storage ${ }^{15}$. Since there is no contact between cold press oil and chemicals and even solvents during refining, the market for cold press vegetable oils is therefore growing ${ }^{16)}$. Cold press oil is more costly than refined oil, there is a tendency to combine it with refined oil to lower production costs in order to gain extraordinary profits.

There are also loose edible oil adulterations across the country. One of India's leading consumer organisations, Consumer Voice, conducted a study that reported up to 85\% adulteration in loose edible oil sold in India across 15 states ${ }^{17)}$. Eight major varieties of edible oil, namely mustard, sesame, coconut, sunflower, palm olein, soybean, groundnut and cottonseed oil, were found to have been adulterated in this study. Coconut oil samples were found to be adulterated at $85 \%$ while cottonseed oil, sesame oil

Table 2 Standards for different edible oils stated in Codex Alimentarius Commission ${ }^{12)}$.

\begin{tabular}{lccccc}
\hline \multicolumn{1}{c}{ Edible oil } & Relative density & Refractive index & $\begin{array}{c}\text { Saponification } \\
\text { value }(\mathrm{mg})\end{array}$ & Iodine value & $\begin{array}{c}\text { Unsaponifiable } \\
\text { matter }(\mathrm{g} / \mathrm{kg})\end{array}$ \\
\hline Coconut oil & $0.908-0.921$ & $1.448-1.450$ & $248-265$ & $6.3-10.6$ & $<15$ \\
Arachis oil & $0.912-0.920$ & $1.460-1.465$ & $187-196$ & $86-107$ & $<10$ \\
Maize oil & $0.917-0.925$ & $1.465-1.468$ & $187-195$ & $103-135$ & $<28$ \\
Olive oil & $0.910-0.916$ & $1.4677-1.4705$ & $184-196$ & $75-94$ & $<15$ \\
Babassu oil & $0.914-0.917$ & $1.448-1.451$ & $245-256$ & $10-18$ & $<12$ \\
Palm oil & $0.891-0.899$ & $1.454-1.456$ & $190-209$ & $50-55$ & $<12$ \\
Palm kernel oil & $0.899-0.914$ & $1.448-1.452$ & $230-254$ & $14.1-21.0$ & $<10$ \\
Palm olein & $0.899-0.920$ & $1.458-1.460$ & $194-202$ & $<56$ & $<13$ \\
Palm stearin & $0.881-0.891$ & $1.447-1.452$ & $193-205$ & $<48$ & $<9$ \\
Cottonseed oil & $0.918-0.926$ & $1.458-1.466$ & $189-198$ & $100-123$ & $<15$ \\
Grapeseed oil & $0.920-0.926$ & $1.467-1.477$ & $188-194$ & $128-150$ & $<20$ \\
Rapeseed oil & $0.910-0.920$ & $1.465-1.469$ & $168-181$ & $94-120$ & $<20$ \\
Safflower seed oil & $0.922-0.927$ & $1.467-1.470$ & $186-198$ & $136-148$ & $<15$ \\
Sesame seed oil & $0.915-0.924$ & $1.465-1.469$ & $186-195$ & $104-120$ & $<20$ \\
Sunflower seed oil & $0.918-0.923$ & $1.461-1.468$ & $188-194$ & $118-141$ & $<15$ \\
Soya bean oil & $0.919-0.925$ & $1.466-1.470$ & $189-195$ & $124-139$ & $<15$ \\
\hline
\end{tabular}


and mustard oil were not any better with $74.07 \%, 74 \%$ and $71.77 \%$ adulteration, respectively, found in this study ${ }^{17)}$. In many cases, it has been found that mineral oil, karanja oil, castor oil, and artificial colours are heavily used in edible oil adulterations ${ }^{18)}$.

\section{Edible Oil Adulteration and Its Effects on Health}

Edible oil often becomes impure and unfit for human consumption as a result of adulteration. It has been reported that adulteration of edible oils resulted in severe health issues in some cases. Azadmard-Damirchi and Torbati reported a Spanish toxic oil syndrome or Spanish olive oil disease, which led to over 600 deaths because non-edible rapeseed oil was sold as an edible oil and even as olive $\mathrm{oil}^{16)}$. Further health problems may also arise if an adulterant used belongs to a specific type of allergens such as peanut oil, as certain buyers may be sensitive to the peanut proteins in the adulterant ${ }^{7)}$.

Adulteration of argemone mexicana seed oil in edible oils has been identified in a number of cases as a cause of epidemic dropsy since it contains Sanguinarine and Dihydrosanguinarine, toxic agents (alkaloids) found in Argemon ${ }^{1)}$. In addition, argemone oil mix with edible oils will not only cause epidemic drowsiness but also glaucoma and loss of eyesight ${ }^{19)}$. It is also reported that edible oil adulterants, argemone oil and butter yellow can cause cancer of the gallbladder ${ }^{20)}$.

Loose edible oil adulterations run the risk of cancer, paralysis, liver damage and cardiac arrest as such oils are heavily adulterated. In the study of Navya et $a l$., it is said that edible oils adulterated with castor oil cause stomach problems ${ }^{18)}$. On the other hand, edible oils that are adulterated with mineral oils can cause liver damage and cause carcinogens ${ }^{18)}$. As a result, with a few recorded cases of health hazards associated with edible oil adulteration, food safety is critical, as with fats and oil authenticity issues.

\section{Technologies for Authentication of Edible Fats and Oils}

\subsection{Chromatography method}

The authenticity of edible oils is commonly evaluated using analytical chemistry methods for the determination of fat phase components. Analysis of the fatty acid composition by gas chromatography is the most widely used $\operatorname{method}(\mathrm{GC})^{21)}$. Based on study from Andrikopoulos et al., olive oil typically contains zero or has very low levels $(<$ $0.5 \%$ ) of these two triglyceride compounds, trilinolein and tripalmitin $^{22}$. Detection of rising amounts of trilinolein or tripalmitin in olive oil by capillary gas chromatography (CGC) with a flame ionisation detector (FID) was used in this study to identify adulteration of olive oil with several seed oils (corn, cottonseed, palm, soybean, and sunflower).

According to Uncu et al., in order to authenticate the botanical origin of olive oil, the chromatographic technique is used to determine whether the fatty acid composition of 11 plant species of edible oil samples deviated from that of olive oil, as mentioned in the Codex Alimentarius Standard $^{23)}$. Linoleic acid was indicated as a fraud determinant to detect adulteration for all mixing ratios evaluated with values that exceeded the threshold of the $1 \%$ as described in the Codex Alimentarius Standard for olive oil. In Jafari et al., fatty acid profiles of olive oil adulterated with three cheap oils, soybean, sunflower, and canola oils were obtained by performing gas chromatographic analysis of fatty acid methyl ester (FAME ${ }^{24)}$. Analyzing the fatty acid profiles obtained through gas chromatographic analysis of FAME, the adulterated olive oils reported higher levels of linolenic and linoleic acids, but significantly lower levels of oleic acids relative to genuine olive oils ${ }^{24)}$. Jabeur et al. have also demonstrated that using gas chromatography and high-performance liquid chromatography to obtain the fatty acid composition of EVOO and adulterated oil samples (Fig. 1 ${ }^{25)}$. It has been suggested that the linolenic acid content observed in the fatty acid compositions could be used as a parameter for the detection of EVOO adulterated with different levels of soybean oil. It has also been shown that the adulteration can be identified by the increase of the trans-fatty acid contents with $3 \%$ of soybean oil, $2 \%$ of corn oil, and $4 \%$ of sunflower oil ${ }^{25)}$.

The capability of solid-phase microextraction (SPME) for the determination of volatile constituents in vegetable oils has occasionally been recognized in the literature by various authors who have insisted on the need to carefully optimise the experimental variables involved in the distillation process ${ }^{26)}$. Krist et al. identified the adulteration of poppy seed oil with sunflower oil using the solid phase microextraction gas chromatography/mass spectrometry (SPME-GC-MS) method ${ }^{27)}$. The analytical method SPME was established in the 1990s as a means of extracting and pre-concentrating pollutants in water ${ }^{28)}$. By using R-pinene as a marker compound, this method, together with the analysis of FAMEs by GC-MS, was able to detect the mixing of sunflower oils in all relevant quantities (5-40\%) in poppy seed oil. Solid phase microextraction and multidimensional gas chromatography were also used in detecting adulteration of olive oil of different varieties with virgin hazelnut oils in percentages of up to $7 \%{ }^{29)}$. This method can be used to detect the presence of $\mathrm{R}$ - and S-enantiomers of filbertone as an indicator in olive oils adulterated with refined hazelnut oil ${ }^{29)}$.

Figure 2 shows the full GC-sterol profile of argan oil. Sterols are useful candidates for identification of edible oil adulteration $^{30)}$. Campesterol is a sterol present in seed oils, which contributes less than $0.4 \%$ of the overall sterol 

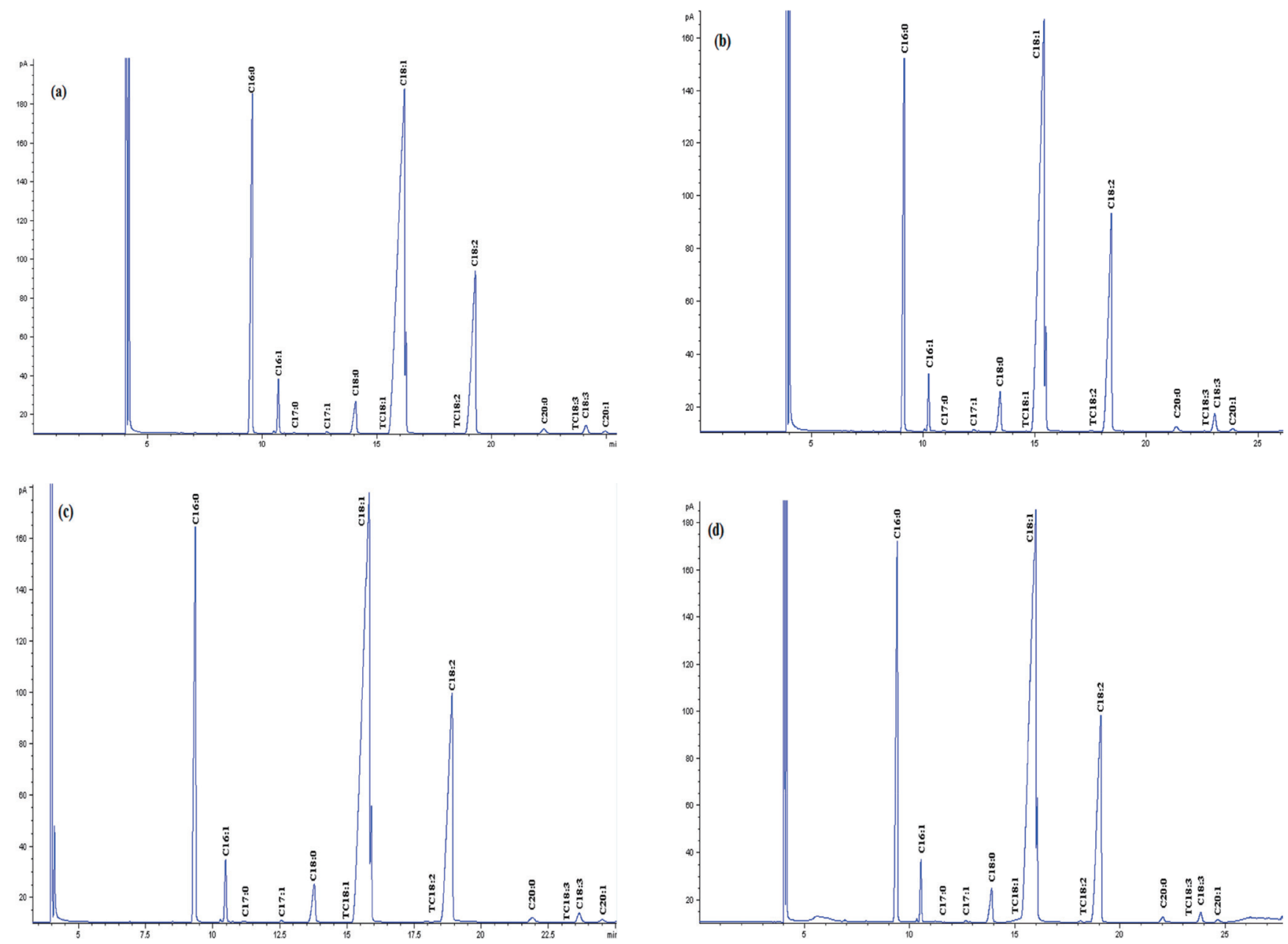

Fig. 1 Gas chromatogram showing the FAMEs profiles of Chemlali EVOO(a) and binary mixtures containing $90 \%$ EVOO and $10 \%$ of either soybean (b), sunflower (c), or corn (d) oils using GC-FID ${ }^{25)}$. cis- and trans-FAMEs were identified a comparison of their retention times versus pure standards analyzed under the same conditions. They were quantified according to their percentage area, obtained by the integration of the peaks. The results were expressed as the percentages of individual fatty acids in the lipid fraction. The linolenic acid percentage could be used as a parameter for the detection of EVOO fraud as well as by the increase of trans-fatty acid contents in the adulterated EVOO.

content of pure argan oil ${ }^{31)}$. Hence, campesterol is selected as the adulteration marker in this research. The method, GLC FID-capillary column in compliance with NP EN ISO 12228:1999 was used to assess the amount of campesterol at a concentration ratio of 99/1,98/2, and 95/5 for mixtures of argan oil and common oils. Evidently, for blending of campesterol-rich common oils with argan oil, campesterol levels above $0.4 \%$ were observed at an adulteration level of $1 \%$ as predicted from the campesterol values measured. This method also assists low campesterol-containing oils in establishing a 95\% purity label for olive oil and hazelnut oil as well as a $98 \%$ purity label for apricot oil. In the research of Salghi et al., high-performance liquid chromatography is performed to obtain triacylglycerol profiles as an indication of adulteration of argan oils with up to $5 \%$ of sunflower, soya bean and olive oil ${ }^{32)}$. This study shows that using highperformance liquid chromatography in conjunction with evaporative light scattering allows researchers to conduct rapid sampling for authenticity assessment. Chromatography methods, however, have number of disadvantages, the most important of which is that they often require complex sample pretreatments which is time consuming. Besides that, these methods require highly qualified personnel, and they are insufficient for screening such adulterated oils with identical fatty acid compositions ${ }^{33)}$.

\subsection{Spectroscopy method}

Spectroscopic methods can also be used to detect adulteration in edible oils, as these methods have the advantage that the time-consuming preparation of the sample is 


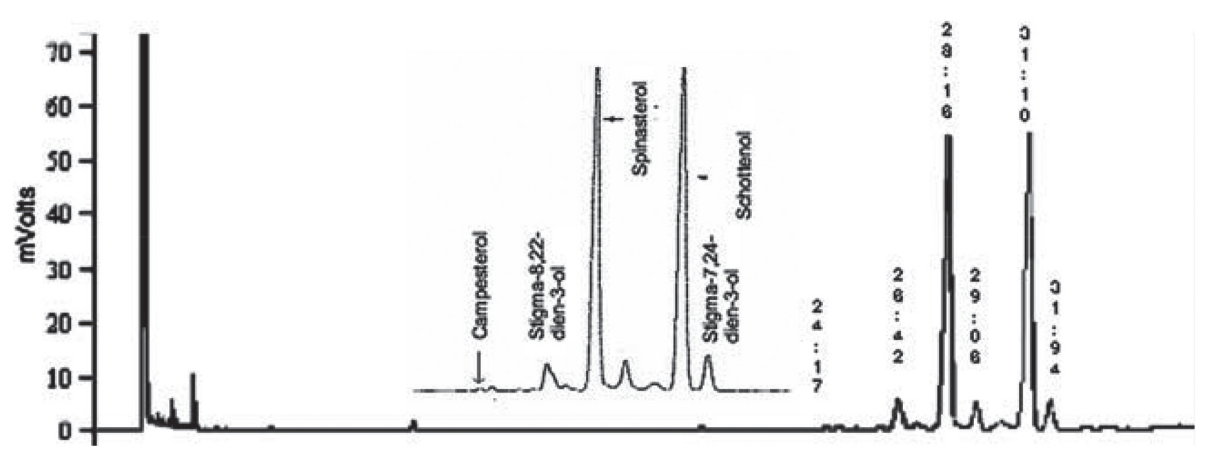

Fig. 2 Full GC-sterol profile of argan oil ${ }^{31)}$. The x-axis of the gas chromatogram shows the amount of time taken for the analytes to pass through the column and reach the mass spectrometer detector. Campesterol retention time $(\mathrm{RT}=$ $24.17 \mathrm{~min}$ ) was clearly distinct from that of other sterols in the GC sterol chromatogram (stigma-8,22-dien-3-ol: RT = $26.42 \mathrm{~min}$, spinasterol: $\mathrm{RT}=28.16 \mathrm{~min}$, schottenol: $\mathrm{RT}=31.10 \mathrm{~min}$, stigmasta-7,24-dien-3-ol: $\mathrm{RT}=31.94 \mathrm{~min}$ ). Sterol quantification was achieved by use of an internal $0.2 \%$ chloroform solution of a-cholestanol. In these conditions, campesterol can be identified through a comparison of a retention time of 24.19 min. Determination of the campesterol level, a sterol found in seed oils, represents less than $0.4 \%$ of argan oil total sterol content can be used as the major analysis method to assess unambiguously argan oil purity up to $98 \%$. The results showed that the argan oil sample in this study contained $0.29 \%$ of campesterol.

usually kept to a minimum. Fourier Infrared Transform (FTIR) spectroscopy has been commonly used in food-related science for more than 15 years. Based on study from Ozulku et al., ATR-FTIR spectroscopy combined with chemometric, principal component analysis (PCA) and cluster analysis allowed detection of adulteration of cold-pressed sesame oil with hazelnut, canola, and sunflower oils in different concentrations ranged from 1 to $50 \%^{34)}$. Rohman and Che Man has also stated that FTIR spectroscopy can be used as a non-destructive and fast technique for the determination of adulteration of cod-liver oil with different concentrations of lard $\left(0.5-50 \% \mathrm{v} / \mathrm{v}\right.$ in cod-liver oil $\left.{ }^{35}\right)$. FTIR combined with a multivariate analysis was also used to detect and measure the adulteration of avocado oils with various edible oils such as sunflower, soybean and canola ${ }^{36}$. Soft Independent Modeling Class Analogy (SIMCA) model was used to discriminate between avocado oil and adulterants (sunflower, canola and soybean oils) based on their chemical analysis (peroxide and iodine value) showed $100 \%$ correct classification rate of the edible oil samples ${ }^{36)}$.

Raman spectroscopy was combined with chemometric methods PCA, principal component regression(PCR), partial least squares (PLS) and artificial neural networks (ANNs) to detect, classify and quantify the adulteration of butter with margarine (Fig. 3) ${ }^{37}$. On the other hand, EVOO samples adulterated with soybean oil, corn oil and sunflower seed oil can also be characterized by using Raman spectroscopy (1000-1800 $\mathrm{cm}^{-1}$ ) and chemometrics, by employing external standard method (ESM) for the quantitative analysis, which was compared with the results obtained by support vector machine (SVM) methods ${ }^{38)}$. Fourier transform (FT)-Raman spectroscopy combined with multivariate procedures has been described as a tool for olive oil au- thentication ${ }^{39)}$. PCR showed $100 \%$ correct discrimination between authentic and adulterated samples and 91.3\% correct classification at various adulteration levels ${ }^{39)}$. Raman spectroscopy with excitation in the visible spectral range coupled with partial least-squares (PLS) regression is a rapid and nondestructive method for monitoring adulteration of extra-virgin olive oil with different levels of sunflower oil ranging from 5 and $100 \%{ }^{40}$.

On the other hand, as it has a low signal-to-noise ratio with rapid spectral acquisition, fluorescence spectroscopy is said to have an advantage over Raman and other spectroscopic techniques. In addition, its sensitivity is also improved by excellent selectivity, which further contributes to its advantages. According to Ali et al., fluorescence spectroscopy (excitation wavelength at $350 \mathrm{~nm}$ ) was applied to identify the adulterant with sunflower oil in pure EVOO in combination with PCA and PLS regression ${ }^{41)}$. In this study, the EVOO is compared and distinguished from sunflower oil by obtaining a fluorescent spectrum containing chlorophyll and carotenoid fingerprints which are characteristics of $\mathrm{EVOO}^{41)}$.

Next, synchronous fluorescence spectroscopy (250-800 nm) combined with three different multivariate methods, namely PCA, soft independent modeling of class analogies (SIMCA) and PLS regression were also used in the study, Karuk Elmas et al. to detect adulteration of cold-pressed grapeseed oil with refined soya bean oil at different adulterant levels from 5 to $50 \%{ }^{42}$. Based on the study, Ntakatsane et al., fluorescence spectroscopy and gas chromatography coupled with PCA and 3-way PLS regression were used in detecting adulteration of pure butterfat with different vegetable oils at various concentrations ranging from $5 \%-40 \%{ }^{43)}$. The detection is achieved by distinguishing 

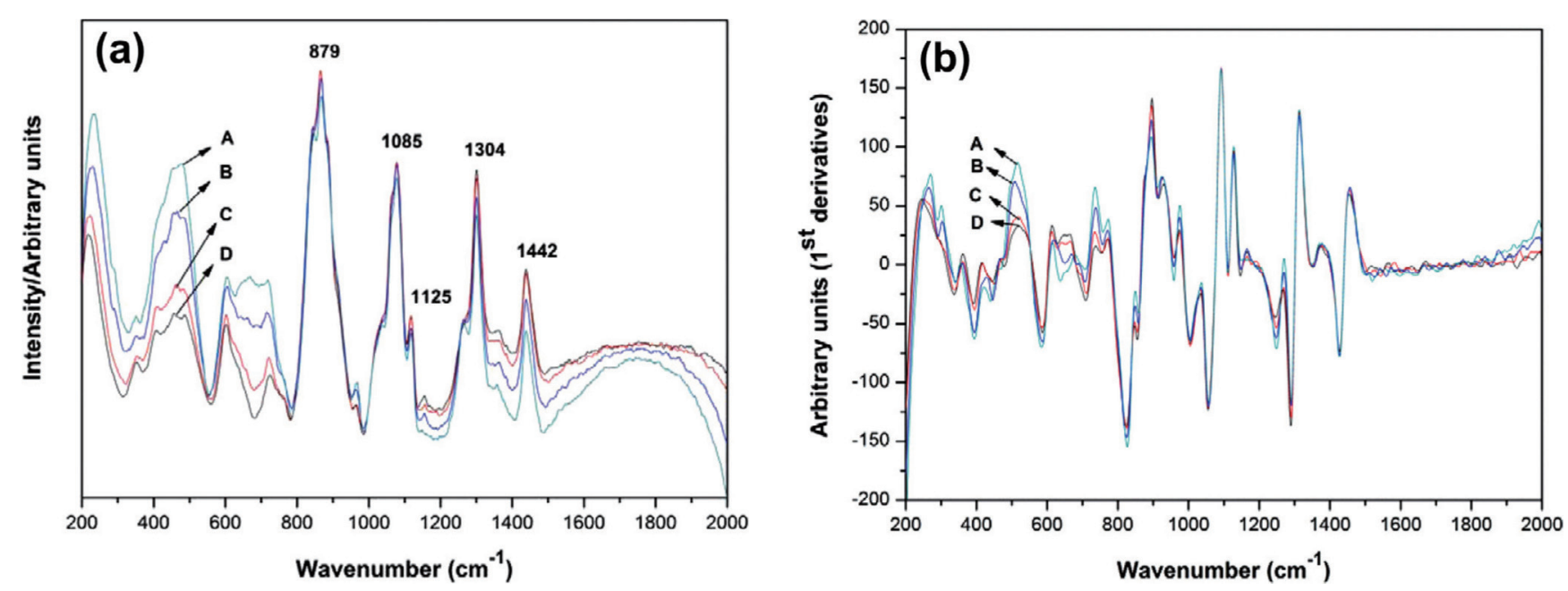

Fig. 3 Original (a) and first-derivative of the Raman spectra (b) of the samples. A: Margarine, B: Butter (20\%) + Margarine $(80 \%)$, C: Butter $(80 \%)+$ Margarine $(20 \%)$, D: Butter ${ }^{37}$. The baseline spectra of adulterated samples and the intensity of band ranges between 380 and $565 \mathrm{~cm}^{-1}$ increased together with the margarine concentrations. In the case of margarine, ratios in adulterated samples were higher, and the spectrum of bands ranging between 570 and $760 \mathrm{~cm}^{-1}$ began to change visibly and two bands $\left(608\right.$ and $\left.730 \mathrm{~cm}^{-1}\right)$ belonging to butter disappeared. Raman spectra of margarine change due to the source of edible oils and added ingredients that cause fluorescence.

between the pure and adulterated samples on the basis of the total concentration of saturated fatty acids and unsaturated fatty acids in the fatty acid compositions, as well as the three main fluorophores: tryptophan, tocopherols and riboflavin.

Chen et al. reported that Near-infrared (NIR) technique combined with competitive adaptive reweighted sampling (CARS) or elastic component regression (ECR) is proved to be feasible for rapidly detecting sesame oil adulterated with other vegetable oils (Fig. 4) ${ }^{44)}$. Basri et al. utilized the short-wave NIR method in two different scan modes, transflectance and transmission mode to compare the accuracy for detecting the presence of lard adulteration in palm $\mathrm{oil}^{45)}$. Based on the result of classification and quantification analysis using soft independent modelling class analogy (SIMCA) and PLS regression, the transmission mode has yield better prediction model compared to the transflectance mode to classify the pure and adulterated palm oil $^{45)}$.

Three experimental setups with PLS regressions, based on near infrared technology (NIR), included a commercial portable NIR, coupled to both reflexion and immersion probes, and a prototype of a multichannel Quasi Imaging Visible NIR spectrometer(QIVN) coupled to an immersion probe were tested for rapid "at-line" assessment of sunflower oil adulterated with different percentages of mineral oil range from $0.5 \%$ to $10 \%$ in work of Picouet et $a l .{ }^{46)}$. Commercial portable NIR, coupled to both reflexion and immersion probes has been shown as the best among the other two experimental setups since it provides satisfactory calibrations and low number of false positives starting

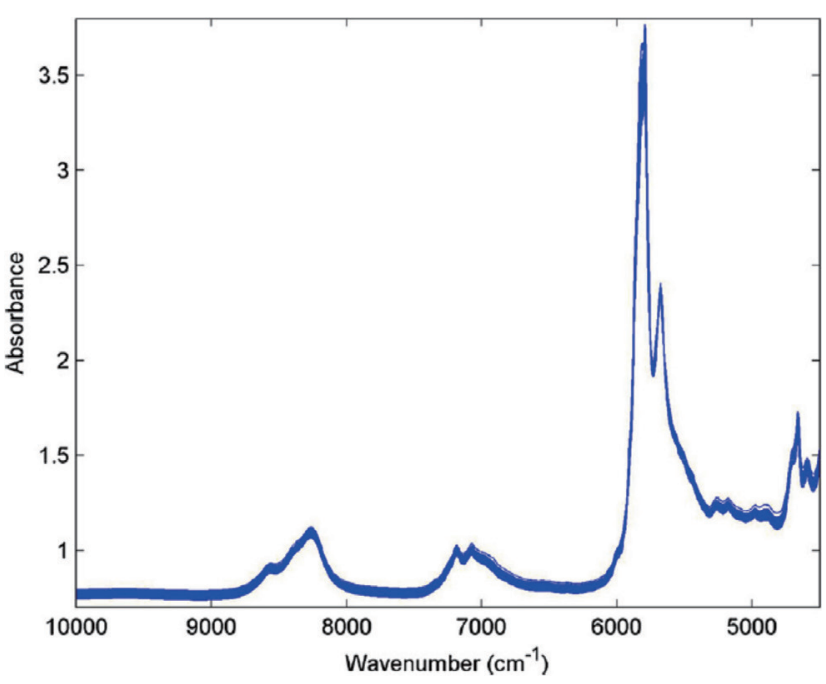

Fig. 4 Near-infrared spectra of sesame oil adulterated by other oils ${ }^{44)}$. By a visual inspection, useful absorption are located in the region of 5600-5900 $\mathrm{cm}^{-1}$. The two peaks around $5791 \mathrm{~cm}^{-1}$ and 5677 $\mathrm{cm}^{-1}$ mainly rise from the first and second overtones of $\mathrm{CH}$ stretching vibrations of $\mathrm{CH}$, $\mathrm{CH} 2$, $\mathrm{CH} 3$, and $\mathrm{CH}=\mathrm{CH}$ in glycerides. The compositions of the vegetable oils vary with the different fatty acids in the glyceride molecules. Different oils have different fatty acid composition and there should be differences in the intensities of bands arising from the overtones and combinations of the $\mathrm{CH} 3$ and $\mathrm{CH} 2$ stretching vibrations. 


\section{H. Tan, I. Kong, U. Irfan et al.}

from levels of mineral oil around $1 \%{ }^{46)}$.

Furthermore, Irfan et al. proposed an interesting handheld NIR spectrometer to detect adulteration palm cooking oil with recycled cooking oil $(\mathrm{RCO})^{47}$. The NIR spectrum calibration was performed using PCA to classify the level of adulteration. i.e. qualitative approach. The result showed that the classification accuracy was $100 \%$ when the concentrations of the recycled cooking oil as adulterant were above $15 \%$. However, the accuracy was low when the concentration of adulteration level was below $15 \%$. This study is considerably innovative to drive a new direction of spectroscopy research since a miniature handheld device was used.

Furthermore, quantification and classification of adulterations in olive oil were proposed in another research ${ }^{48)}$. Corn and sunflower oil were used as adulterants in the olive oil. It was reported that there was no misclassification error in discriminant analysis used to distinguish between pure EVOO and adulterated with corn oil and sunflower oil. Furthermore, high $\mathrm{R}^{2}$ value was also obtained to quantify the level of sunflower oil adulterated olive oil samples. PLS was used for calibration of the FTIR spectrum collected during the experiment. The FTIR spectrometer was a tabletop portable type of instrument equipped with Attenuated Total Reflectance (ATR) kit to produce deep penetration in infrared beam of $2 \mu \mathrm{m}$.

Another attempt to detect adulteration in olive oil was also proposed with NIR spectroscopy instrument combined with PCA and SIMCA for calibration ${ }^{7)}$. Various type of oils was used as adulterants. The PCA scores plot showed separation between the adulterated mixtures and the unadulterated sample, which demonstrated that the developed method could detect as low as $2.7 \% \mathrm{w} / \mathrm{w}$ adulteration if an unadulterated sample of the oil in question was provided. Lower limits of adulteration detection for corn, sunflower, soybean, and canola oils were found to be approximately 20\%, 20\%, 15\%, and 10\%, respectively.

While high-resolution nuclear-magnetic resonance (NMR) spectroscopy is an expensive instrumentation and not commonly available, it has grown in popularity with lipid scientists. Fragaki et al. reported that three grades of olive oils were able to be classified by combining two multivariate statistical methods, hierarchical cluster analysis and decision analysis, by applying High-field ${ }^{31}$ P NMR (202.2 $\mathrm{MHz}$ ) spectroscopy ${ }^{49)}$. Agiomyrgianaki et al. used NMR spectroscopy for the detection of refined olive oil adulterated with refined hazelnut oil ${ }^{50)}$. In this study, the refined oils were classified based on their fatty acids content and the concentration of their minor compounds by using the forward stepwise canonical discriminant analysis and the classification binary trees.

Proton NMR spectroscopy combined with PCA and PLS was further applied for detection of adulteration of camellia oil with three different cheap vegetable oils at different percentages ranging from $5 \%$ to $80 \%{ }^{51)}$. The slight difference between these oils was also demonstrated using a discriminant analysis with an identification accuracy of more than $90 \%$ in this research ${ }^{50)}$. As the summarizing part of this section, Table 3 shows the research review in the edible oils' adulteration detection using spectroscopy method. Despite the fact that the spectrometric method has been proposed as a simple and fast detection method, it is difficult to achieve complete characterization of a sample's quality $^{33)}$. Furthermore, while NMR methods have the advantages of being quick and nondestructive analytical methods, their application fields are limited due to the high cost of the instruments ${ }^{33)}$.

\subsection{Electrochemical Sensor method}

Electronic nose came on the market decades ago and it is preferred to routine laboratory analysis because it is fast and easy-to-handle ${ }^{52)}$. They are designed to identify and differentiate between complex odours from food samples using a sensor array consisting of widely tuned (non-specific) sensors treated with various chemical or biochemical substances that are sensitive to odours ${ }^{53)}$. The characteristic fingerprint or odour printing will then be generated by an odour stimulus from the group of sensors. These patterns from recognised odours are then used to create a database that is subjected to multivariate analysis in order to identify and classify unknown odours. Metal-oxide gas sensors, metal-oxide semiconductor field effect transistors, acoustic wave gas sensors, electrochemical gas sensors, quartz crystal microbalance sensors, polymer gas sensors, surface acoustic wave devices, field-effect gas sensors, fiber-optic gas sensors and others are all types of electrochemical sensors. They are all available in various types of sensor coating materials, which are categorised according to the additive doping materials, the form and function of the chemical.

Adulteration of EVOO with rapeseed and sunflower oils can also be detected by using electronic nose based on metal oxide sensors (HS-E nose) and by direct coupling of SPME to MS (SPME-MS) ${ }^{54)}$. By applying PCA and PLS analysis to the data, excellent results in predicting the adulteration percentage of the samples were achieved in the study.

Electronic nose is also proven to be very efficient in distinguishing between virgin olive oil(VOO) samples adulterated with different percentages of hazelnut oil by combining data analysis of volatile substances by using the $\mathrm{PCA}^{54)}$. In this research, virgin olive oil (VOO) adulterated with 5 to $50 \%$ hazelnut oil was successfully detected by applying this method. Use of surface acoustic wave sensing electronic nose, was able to produce a two-dimensional olfactory image called VaporPrint ${ }^{\mathrm{TM}}$ for detection of adulteration in refined, bleached, deodorized (RBD) palm olein with lard. 
Table 3 Summary of research in edible oils adulteration detection using spectroscopy method.

\begin{tabular}{|c|c|c|c|c|c|}
\hline \multirow[b]{2}{*}{ Authors } & \multirow[b]{2}{*}{ Oil sample } & \multirow[b]{2}{*}{ Adulterants } & \multirow[b]{2}{*}{ Instrument } & \multicolumn{2}{|c|}{ Calibration method } \\
\hline & & & & $\begin{array}{l}\text { Quantitative } \\
\text { (regression) }\end{array}$ & Classification \\
\hline Ozulku et al..$^{34)}$ & $\begin{array}{l}\text { Cold-press sesame } \\
\text { oil }\end{array}$ & $\begin{array}{l}\text { hazelnut, canola, and } \\
\text { sunflower oils }\end{array}$ & FTIR-ATR spectroscopy & PLS & $\begin{array}{l}\text { PCA and Cluster } \\
\text { analysis }\end{array}$ \\
\hline $\begin{array}{l}\text { Rohman and Che } \\
\operatorname{Man}^{48)}\end{array}$ & $\begin{array}{l}\text { Extra virgin olive } \\
\text { oil }\end{array}$ & $\begin{array}{l}\text { Corn oil and sunflower } \\
\text { oils }\end{array}$ & FTIR-ATR spectroscopy & PLS & $\begin{array}{l}\text { Discriminant analysis } \\
\text { (DA) }\end{array}$ \\
\hline $\begin{array}{l}\text { Rohman and Che } \\
\operatorname{Man}^{35}\end{array}$ & Cod-liver oil & Animal fat (lard) & FTIR-ATR spectroscopy & PLS & $\begin{array}{l}\text { Discriminant analysis } \\
\text { (DA) }\end{array}$ \\
\hline $\begin{array}{l}\text { Quiñones-Islas et } \\
a l^{36)}\end{array}$ & Avocado oil & $\begin{array}{l}\text { Sunflower, canola and } \\
\text { soybean oils }\end{array}$ & Mid-FTIR spectroscopy & PLS & SIMCA \\
\hline Uysal et $a l .{ }^{37)}$ & Butter & Margarine & Raman spectroscopy & $\begin{array}{l}\text { PLS and } \\
\text { ANN }\end{array}$ & PCA \\
\hline Zhang et al. ${ }^{38)}$ & $\begin{array}{l}\text { Extra virgin olive } \\
\text { oil }\end{array}$ & $\begin{array}{l}\text { Soybean, corn and } \\
\text { sunflower seed oils }\end{array}$ & Raman spectroscopy & $\begin{array}{l}\text { ESM and } \\
\text { SVM }\end{array}$ & N/A \\
\hline El-Abassy et al. ${ }^{40)}$ & $\begin{array}{l}\text { Extra virgin olive } \\
\text { oil }\end{array}$ & Sunflower oil & Vis-Raman spectroscopy & PLS & PCA \\
\hline Ali et $a l^{41)}$ & $\begin{array}{l}\text { Extra virgin olive } \\
\text { oil }\end{array}$ & Sunflower oil & Fluorescence spectroscopy & PLS & PCA \\
\hline $\begin{array}{l}\text { Karuk Elmas et } \\
a l .{ }^{42)}\end{array}$ & $\begin{array}{l}\text { cold pressed grape } \\
\text { seed oil }\end{array}$ & Refined soybean oil & $\begin{array}{l}\text { synchronous fluorescence } \\
\text { spectroscopy }\end{array}$ & PLS & PCA and SIMCA \\
\hline Ntakatsane et al. ${ }^{43)}$ & Butterfat & Vegetable oils & Fluorescence spectroscopy & PLS & PCA \\
\hline Basri et $a l^{45)}$ & Palm cooking oil & Lard oil & $\begin{array}{l}\text { Portable MicroNIR } \\
\text { spectroscopy }\end{array}$ & $\begin{array}{l}\text { PLS with } \\
\text { CARS }\end{array}$ & SIMCA \\
\hline Picouet et al. ${ }^{46)}$ & Sunflower oil & Mineral oils & $\begin{array}{c}\text { Quasi Imaging Visible NIR } \\
\text { spectrometer }\end{array}$ & PLS & N/A \\
\hline Irfan et al. ${ }^{47)}$ & Palm cooking oil & Recycled cooking oil & $\begin{array}{l}\text { Handheld Micro-NIR } \\
\text { spectrometer }\end{array}$ & N/A & PCA \\
\hline Vanstone et $a l^{7}{ }^{7}$ & $\begin{array}{l}\text { Extra virgin olive } \\
\text { oil }\end{array}$ & $\begin{array}{c}\text { corn, sunflower, } \\
\text { soybean, and canola oils }\end{array}$ & NIR spectroscopy & N/A & PCA \\
\hline $\begin{array}{l}\text { Agiomyrgianaki et } \\
a l .{ }^{50)}\end{array}$ & Olive oil & Refined hazelnut oil & NMR spectroscopy & N/A & $\begin{array}{c}\text { canonical DA and } \\
\text { classification binary } \\
\text { trees (CBTs) }\end{array}$ \\
\hline Shi et al. ${ }^{51)}$ & camellia oil & 3 types of vegetable oils & $\begin{array}{l}\text { 1H Proton NMR } \\
\text { spectroscopy }\end{array}$ & PLS & $\begin{array}{l}\text { PCA and orthogonal } \\
\text { projection to latent } \\
\text { structures DA (OPLS- } \\
\text { DA) }\end{array}$ \\
\hline Fragaki et al. ${ }^{49)}$ & $\begin{array}{l}\text { Extra virgin olive } \\
\text { oil }\end{array}$ & $\begin{array}{l}\text { lampante olive oil and } \\
\text { refined olive oil }\end{array}$ & NMR spectroscopy & N/A & $\begin{array}{c}\text { Discriminant analysis } \\
\text { (DA) }\end{array}$ \\
\hline
\end{tabular}

Electronic noses can also be used to identify and distinguish lard from other kinds of animal fats as well as from foods containing lard ${ }^{55)}$. VaporPrint showed the results obtained when the radial angles of the two-dimensional olfactory image representing the sensor yield individual patterns (smell prints) of the odour of various animal body fats. In Nurjuliana et al., the PCA was applied to analyse the results obtained and resulted in a satisfactory grouping of samples that also enhances the ability to detect the presence of lard in food items that will assist Halal authentica- tion in the future ${ }^{55)}$. Surface acoustic wave sensing electronic nose was used to detect adulteration of virgin coconut oil with refined, bleached and deodorized palm kernel olein at a level of adulteration from 1 to $20 \%$ by generating a pattern of volatile compounds present in the samples (Fig. 5 ${ }^{56)}$. By utilizing this device helped the research to obtain a fingerprint of volatile compounds occurring in the oil samples. Nonetheless, in this research, PCA was also used to differentiate between adulterated virgin coconut oil with different levels of refined, bleached and 


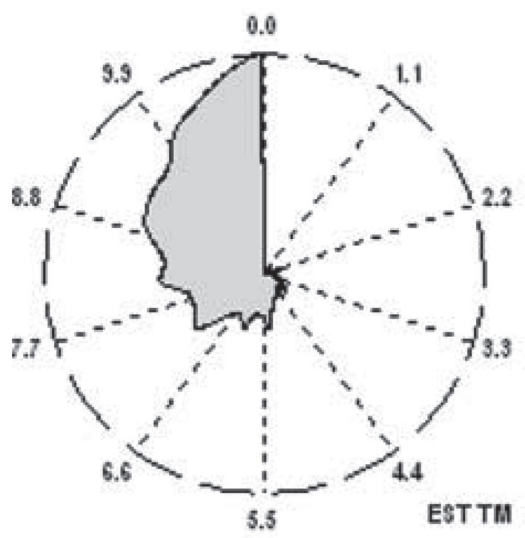

virgin coconut oil

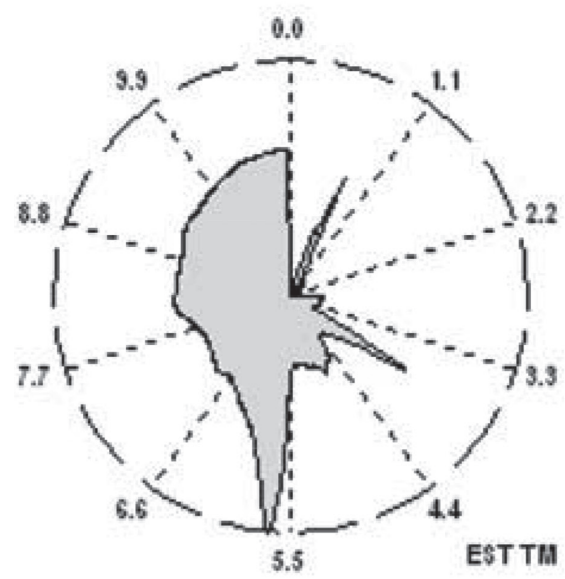

$20 \%$ of palm kernel olein

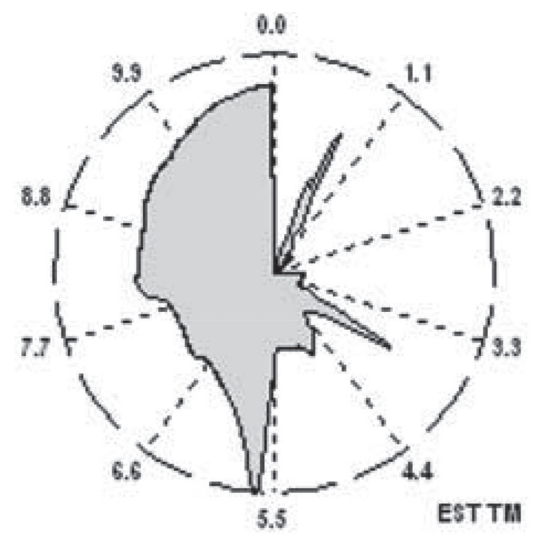

$8 \%$ of palm kernel olein

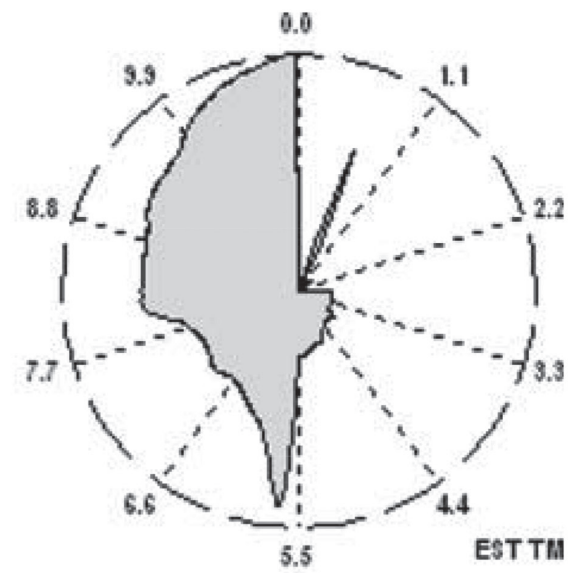

palm kernel olein

Fig. 5 VaporPrint ${ }^{\mathrm{TM}}$ of virgin coconut oil adulterated with different percentages of RBD palm kernel olein ${ }^{56)}$. The changes that occurred as palm kernel olein was slowly added to virgin coconut oil were able to be monitored qualitatively by the VaporPrint ${ }^{\mathrm{TM}}$ image. This image can be interpreted as the chemical signature of a substance's smell. As virgin coconut oil was slowly adulterated by RBD palm kernel olein, the VaporPrint ${ }^{\mathrm{TM}}$ image changed accordingly with the aroma pattern slowly becoming more like the VaporPrint ${ }^{\mathrm{TM}}$ of the adulterant as the percentage of adulteration increased.

deodorised palm kernel olein and pure virgin coconut oil, with satisfactory results obtained.

The idea of electronic tongues (E-tongue) or taste sensors has grown rapidly in recent years due to their high potential. Electronic tongues may be viewed as wet alternatives of e-noses. The performance of a non-specific array of sensors reveals various patterns for different taste-causing chemical substances and the resulting data is statistically processed ${ }^{53}$. The performance pattern is determined by the different selectivity of the individual sensing units and is associated with a particular taste or quality feature. The electronic tongue consisted of a double working electrode (platinum and gold), an auxiliary and a reference electrode onto which both large amplitude pulse voltammetry (LAPV) and small amplitude pulse voltammetry
(SAPV) were applied ${ }^{54)}$. It is further developed into a different configuration consisting of five working electrodes (gold, iridium, palladium, platinum and rhodium), a reference electrode and an auxiliary electrode of stainless steel $^{57)}$. Electronic tongue has been used for a wide variety of applications, including the detection of adulteration in edible oils due to their robustness and simplicity.

Whether mislabelled or blended with cheaper olive and seed oils, the high price of EVOOs and virgin olive oils (VOOs) make them perfect "candidates" for adulteration. According to Apetrei and Apetrei, the use of voltammetric e-tongue has been shown for the first time to detect adulteration in EVOO with different concentrations of sunflower oil, corn oil and soybean oil(Fig. 6) ${ }^{57}$. In this research, PCA, partial least squares discriminant analysis (PLS-DA) 

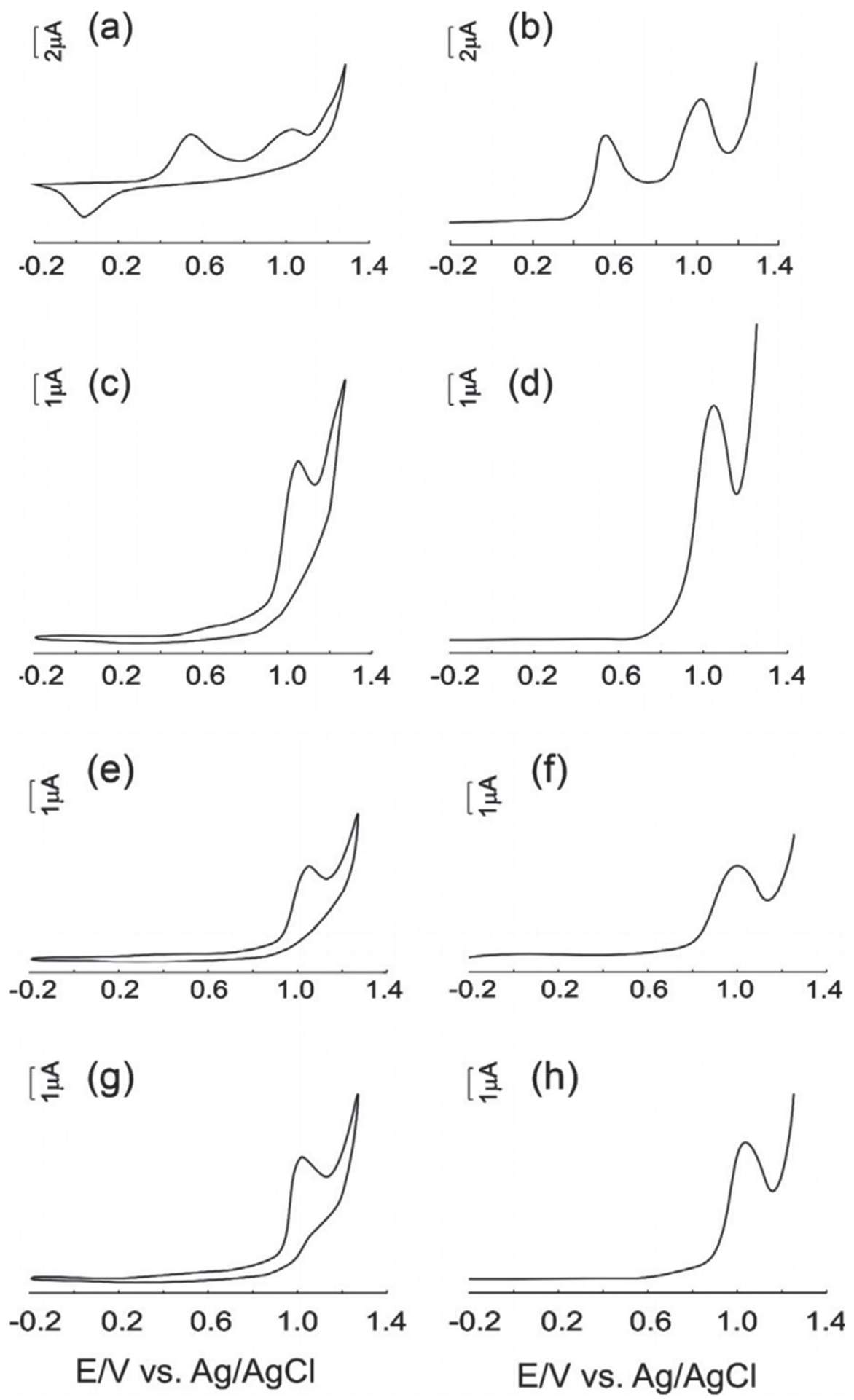

Fig. 6 Voltametric responses of voltammetric e-tongue, EO carbon paste-based sensors ${ }^{57)}$. Voltammetric measurements were carried out by means of Square wave voltammetry (SWV). Preliminary studies and stabilization of the sensor signals by cyclic voltammetry (CV). EVOO carbon paste-based sensors: (a) CV; (b) SWV. Sf carbon paste-based sensors: (c) CV; (d) SWV. S carbon paste-based sensors: (e) CV; (f) SWV. C carbon paste-based sensors: (g) CV; (h) SWV. The voltammetric curves indicate that the nature and concentration of electroactive compounds found in different edible oils bearing a diversity of electrochemical signals. The voltammetric responses can be used to discriminate edible oils. From the analyse of the voltammetric curves it can be observed that EVOO related curves can be easily distinguished from other oils. 
and PLS regression were also applied to e-tongue data showed the capability of this device to discriminate pure oils (an EVOO and three seed oils) according to their botanical origins, to predict total polyphenolic content of binary mixtures of EVOO and seed oils, to classify the adulterated EVOOs when the concentration of adulterant oil was over $5 \%$ and to estimate the composition of EVOO and seed oil mixtures within the range 2-25\% range. By the combination of the use of a voltammetric e-tongue and an e-nose based on metal oxide semiconductor sensors and pattern recognition technique, argan oil adulterated with different concentrations of sunflower oil can be detected in the work of Bougrini ${ }^{58)}$. However, there is a limited selection of commercially available electrochemical sensors on the market. Furthermore, such electrochemical sensors are typically stationary, necessitate specific measurement conditions, and are costly to manufacture and maintain ${ }^{59)}$.

\section{Conclusion}

With fast distribution systems globally, adulterants that are added intentionally in edible oils can cause severe economy and health consequences. The detection of edible oils adulteration is one of the ways to establish food defense, in which food security and resilience can be enhanced. This paper outlined the regulatory compliance for edible oils in some countries and critically reviewed the detection technologies available such as SPME-GC-MS, NIR, NMR, FTIR, electronic nose and tongue. The continued development of new technologies or enhancement of current methods are essential so that food supply chain can be monitored more effectively.

\section{References}

1) Yadav, S. Edible oil adulterations: Current issues, detection techniques, and health hazards. Int. J. Chem. Stud. 6, 1393-1397 (2018).

2) Khir, M.F.A. Detecting beef tallow adulteration in palm oil with nir spectroscopy and chemometrics analysis. IJIE 10, 157-160 (2018).

3) Zhao, H.; Wang, Y.; Xu, X.; Ren, H.; Li, L.; Xiang, L.; Zhong, W. Detection of adulterated vegetable oils containing waste cooking oils based on the contents and ratios of cholesterol, $\beta$-sitosterol, and campesterol by gas chromatography/mass spectrometry. J. AOAC Int. 98, 1645-1654(2015).

4) ICAR, Handbook of Agriculture, $6^{\text {th }}$ edition, Directorate of Information and Publication of Agriculture, New Delhi, pp. 1120-1194(2016).

5) Marikkar, J.M.N.; Lai, O.M.; Ghazali, H.M.; Che Man, Y.B. Detection of lard and randomized lard as adulter- ants in refined-bleached-deodorized palm oil by differential scanning calorimetry. J. Am. Oil Chem. Soc. 78, 1113-1119 (2001).

6) Mottram, H.R.; Woodbury, S.E.; Rossell, J.B.; Evershed, R.P. High-resolution detection of adulteration of maize oil using multi-component compound-specific $\delta 13 \mathrm{C}$ values of major and minor components and discriminant analysis. Rapid Commun. Mass Spectrom. 17, 706-712 (2003).

7) Vanstone, N.; Moore, A.; Martos, P.; Neethirajan, S. Detection of the adulteration of extra virgin olive oil by near-infrared spectroscopy and chemometric techniques. FQS 2, 189-198 (2018).

8) Kou, Y.; Li, Q.; Liu, X.; Zhang, R.; Yu, X. Efficient detection of edible oils adulterated with used frying oils through pe-film-based ftir spectroscopy combined with DA and PLS. J. Oleo Sci. 67, 1083-1089(2018).

9) Indian Trade Portal, Thailand revised standards for edible fats and oil to comply with relevant Codex standards. 30 November 2020 (2014).

10) Ministry of Health and Family Welfare, Food Safety and Standards Authority of India(FSSAI). The Gazette of India: Extraordinary 3, p. 330 (2011).

11) Public Health (Food) Regulations, Public Health (Food) Act 2001 Edition. Chapter 182, 56-63.

12) Codex Alimentarius Commission, Codex alimentarius: Standard for edible fats and oils not covered by individual standards. Rome: World Health Organization: Food and Agriculture Organization of the United Nations (2007).

13) Siger, A.; Nogala-Kalucka, M.; Lampart-Szczapa, F. The content and antioxidant activity of phenolic compounds in cold pressed oils. J. Food Lipids 15, 137149 (2008).

14) Rossell, J.B. Purity criteria in edible oils and fats. Fat Sci. Technol. 93, 526-531(1991).

15) Ulberth, F.; Buchgraber, M. Authenticity of fats and oils. Eur. J. Lipid Sci. Technol. 102, 687-694(2000).

16) Azadmard-Damirchi, S.; Torbati, M. Adulterations in some edible oils and fats and their detection methods. J. Food Qual. Hazards Control 2, 38-44(2015).

17) The New Indian Express, "85 Per cent adulteration in loose edible oil'. https://www.newindianexpress.com/ lifestyle/health/2018/jun/12/85-per-cent-adulterationin-loose-edible-oil-1826744.html Accessed 30 November 2020 (2020).

18) Navya, P.; Raju, K.; Sukumaran, M.K. Analysis of food adulterants in selected food items purchased from local grocery stores. IJASR 3, 82-89 (2017).

19) Das, M.; Khanna, S.K. Clinico epidemiological, toxicological, and safety evaluation studies on argemone oil. Crit. Rev. Toxicol. 27, 273-297(1997).

20) Mishra, V.; Mishra, M.; Ansari, K.M.; Chaudhari, B.P.; Khanna, R.; Das, M. Edible oil adulterants, argemone 
oil and butter yellow, as aetiological factors for gall bladder cancer. Eur. J. Cancer. 48, 2075-2085(2012).

21) Yang, Y.; Ferro, M.D.; Cavado, I.; Liang, Y. Detection and identification of extra virgin olive oil adulteration by gc-ms combined with chemometrics. J. Agric. Food Chem. 61, 3693-3702 (2013).

22) Andrikopoulos, N.K.; Giannakis, I.G.; Tzamtzis, V. Analysis of olive oil and seed oil triglycerides by capillary gas chromatography as a tool for the detection of the adulteration of olive oil. J. Chromatogr. Sci. 39, 137-145 (2001).

23) Uncu, A.T.; Uncu, A.O.; Frary, A.; Doganlar, S. Barcode DNA length polymorphisms vs fatty acid profiling for adulteration detection in olive oil. Food Chem. 221, 1026-1033 (2017).

24) Jafari, M.; Kadivar, M.; Keramat, J. Detection of adulteration in iranian olive oils using instrumental (GC, NMR, DSC) Methods. J. Am. Oil Chem. Soc. 86, 103110 (2008).

25) Jabeur, H.; Zribi, A.; Makni, J.; Rebai, A.; Abdelhedi, R.; Bouaziz, M. Detection of chemlali extra-virgin olive oil adulteration mixed with soybean oil, corn oil, and sunflower oil by using GC and HPLC. J. Agric. Food Chem. 62, 4893-4904 (2014).

26) Vichi, S.; Castellote, A.I.; Pizzale, L.; Conte, L.S.; Buxaderas, S.; López-Tamames, E. Analysis of virgin olive oil volatile compounds by headspace solid-phase microextraction coupled to gas chromatography with mass spectrometric and flame ionization detection. $J$. Chromatogr. A. 983, 19-33(2003).

27) Krist, S.; Stuebiger, G.; Bail, S.; Unterweger, H. Detection of adulteration of poppy seed oil with sunflower oil based on volatiles and triacylglycerol composition. J. Agric. Food Chem. 54, 6385-6389 (2006).

28) Arthur, C.; Pawliszyn, J. SPME with thermal desorption using fused silica fibres. Anal. Chem. 62, 21452148 (1990).

29) Flores, G.; Ruiz del Castillo, M.L.; Blanch, G.P.; Herraiz, M. Detection of the adulteration of olive oils by solid phase microextraction and multidimensional gas chromatography. Food Chem. 97, 336-342 (2006).

30) Amaral, J.S.; Casal, S.; Citova, I.; Santos, A.; Seabra, R.M.; Oliveira, B.P.P. Characterization of several hazelnut (Corylus avellana L.) cultivars based in chemical, fatty acid and sterol composition. Eur. Food Res. Technol. 222, 274-280 (2006).

31) Hilali, M.; Charrouf, Z.; Soulhi, A.E.A.; Hachimi, L.; Guillaume, D. Detection of argan oil adulteration using quantitative campesterol gc-analysis. J. Am. Oil Chem. Soc. 84, 761-764(2007).

32) Salghi, R.; Armbruster, W.; Schwack, W. Detection of argan oil adulteration with vegetable oils by high-performance liquid chromatography-evaporative light scattering detection. Food Chem. 153, 387-392
(2014).

33) Tian, L.; Zeng, Y.; Zheng, X.; Chiu, Y.; Liu, T. Detection of peanut oil adulteration mixed with rapeseed oil using gas chromatography and gas chromatography-ion mobility spectrometry. Food Anal. Methods 12, 2282$2292(2019)$.

34） Ozulku, G.; Yildirim, R.M.; Toker, O.S.; Karasu, S.; Durak, M.Z. Rapid detection of adulteration of cold pressed sesame oil adulterated with hazelnut, canola, and sunflower oils using ATR-FTIR spectroscopy combined with chemometric. Food Control 82, 212-216 (2017).

35) Rohman, A.; Che Man, Y.B. Analysis of cod-liver oil adulteration using fourier transform infrared (FTIR) spectroscopy. J. Am. Oil Chem. Soc. 86, 1149-1153 (2009).

36) Quiñones-Islas, N.; Meza-Márquez, O.G.; Osorio-Revilla, G.; Gallardo-Velazquez, T. Detection of adulterants in avocado oil by Mid-FTIR spectroscopy and multivariate analysis. Food Res. Int. 51, 148-154 (2013).

37) Uysal, R.S.; Boyaci, I.H.; Genis, H.E.; Tamer, U. Determination of butter adulteration with margarine using Raman spectroscopy. Food Chem. 141, 4397-4403 (2013).

38) Zhang, X.F.; Zou, M.Q.; Qi, X.H.; Liu, F.; Zhang, C.; Yin, F. Quantitative detection of adulterated olive oil by Raman spectroscopy and chemometrics. J. Raman Spectrosc. 42, 1784-1788(2011).

39) Baeten, V.; Meurens, M.; Morales, M.T.; Aparicio, R. Detection of virgin olive oils adulteration by fourier transform raman spectroscopy. J. Agric. Food Chem. 44, 2225-2230 (1996).

40) El-Abassy, R.M.; Donfack, P.; Materny, A. Visible Raman spectroscopy for the discrimination of olive oils from different vegetable oils and the detection of adulteration. J. Raman Spectrosc. 40, 1284-1289 (2009).

41) Ali, H.; Saleem, M.; Anser, M.R.; Khan, S.; Ullah, R.; Bilal, M. Validation of fluorescence spectroscopy to detect adulteration of edible oil in extra virgin olive oil (evoo) by applying chemometrics. Appl. Spectrosc. 000370281876848(2018).

42) Karuk Elmas, Ş.N.; Arslan, F.N.; Akin, G.; Kenar, A.; Janssen, H.G.; Yilmaz, I. Synchronous fluorescence spectroscopy combined with chemometrics for rapid assessment of cold-pressed grape seed oil adulteration: qualitative and quantitative study. Talanta 196, 22-31 (2018).

43) Ntakatsane, M.P.; Liu, X.M.; Zhou, P. Short communication: Rapid detection of milk fat adulteration with vegetable oil by fluorescence spectroscopy. J. Dairy Sci. 96, 2130-2136 (2013).

44) Chen, H.; Lin, Z.; Tan, C. Fast quantitative detection of sesame oil adulteration by near-infrared spectroscopy and chemometric models. Vib. Spectrosc. 99, 178-183 
(2018).

45) Basri, K.N.; Hussain, M.N.; Bakar, J.; Sharif, Z.; Khir, M.F.A.; Zoolfakar, A.S. Classification and quantification of palm oil adulteration via portable NIR spectroscopy. Spectrochim. Acta A. Mol. Biomol. Spectrosc. 173, 335-342 (2017).

46) Picouet, P.A.; Gou, P.; Hyypiö, R.; Castellarim, M. Implementation of NIR technology for at-line rapid detection of sunflower oil adulterated with mineral oil. $J$. Food Eng. 230, 18-27 (2018).

47) Irfan, U.B.; Pui, L.P.; Solihin, M.I. Feasibility study of detecting palm oil adulteration with recycled cooking oil using a handheld NIR spectroscopy. AIP Conf. Proceed. 2306, 020019 (2020).

48) Rohman, A.; Che Man, Y.B. Quantification and classification of corn and sunflower oils as adulterants in olive oil using chemometrics and FTIR spectra. Scientific World J. 2012, 250795 (2012).

49) Fragaki, G.; Spyros, A.; Siragakis, G.; Salivaras, E.; Dais, P. Detection of extra virgin olive oil adulteration with lampante olive oil and refined olive oil using nuclear magnetic resonance spectroscopy and multivariate statistical analysis. J. Agric. Food Chem. 53, 2810-2816 (2005).

50) Agiomyrgianaki, A.; Petrakis, P.V.; Dais, P. Detection of refined olive oil adulteration with refined hazelnut oil by employing NMR spectroscopy and multivariate statistical analysis. Talanta 80, 2165-2171(2010).

51) Shi, T.; Zhu, M.; Chen, Y.; Yan, X.; Chen, Q.; Wu, X.; Xie, M. 1 H NMR combined with chemometrics for the rapid detection of adulteration in camellia oils. Food Chem. 242, 308-315 (2018).

52) Biswas, S.; Heindselmen, K.; Wohltjen, H.; Staff, C. Differentiation of vegetable oils and determination of sunflower oil oxidation using a surface acoustic wave sensing device. Food Control 15, 19-26 (2004).
53) Peris, M.; Escuder-Gilabert, L. Electronic noses and tongues to assess food authenticity and adulteration. Trends Food Sci. Technol. S0924224416302862 (2016).

54) Mildner-Szkudlarz, S.; Jelen, H.H. The potential of different techniques for volatile compounds analysis coupled with PCA for the detection of the adulteration of olive oil with hazelnut oil. Food Chem. 110, 751-761 (2008).

55) Nurjuliana, M.; Che Man, Y.B.; Mat Hashim, D. Analysis of lard's aroma by an electronic nose for rapid Halal authentication. J. Am. Oil Chem. Soc. 88, 75-82 (2011).

56) Marina, A.M.; Che Man, Y.B.; Amin, I. Use of the SAW sensor electronic nose for detecting the adulteration of virgin coconut oil with RBD palm kernel olein. $J$. Am. Oil Chem. Soc. 87, 263-270 (2010).

57) Apetrei, I.M.; Apetrei, C. Detection of virgin olive oil adulteration using a voltammetric e-tongue. Comput. Electron. Agric. 108, 148-154(2014).

58) Bougrini, M.; Tahri, K.; Haddi, Z.; Saidi, T.; El Bari, N.; Bouchikhi, B. Detection of adulteration in argan oil by using an electronic nose and a voltammetric electronic tongue. J. Sens. 1-10 (2014).

59） Majchrzak, T.; Wojnowski, W.; Dymerski, T.; Gębicki, J.; Namieśnik, J. Electronic noses in classification and quality control of edible oils: A review. Food Chem. 246, 192-201 (2018).

CC BY 4.0 (Attribution 4.0 International). This license allows users to share and adapt an article, even commercially, as long as appropriate credit is given. That is, this license lets others copy, distribute, remix, and build upon the Article, even commercially, provided the original source and Authors are credited. 